PALABRAS CLAVE

Mujeres cabeza de familia Madres solteras

Ingresos

Mercado de trabajo

Composición familiar

Pobreza

Costa Rica

T.H. Gindling

University of Maryland,

Baltimore County

e Investigador visitante en el

Instituto de Investigaciones en

Ciencias Económicas,

Universidad de Costa Rica

o gindling@umbc.edu

Luis Oviedo

Instituto de Investigaciones

en Ciencias Económicas,

Universidad de Costa Rica

œloviedo@cariari.ucr.ac.cr
REVISTA DE LA CEPAL 94 ABRIL 2008

\section{Hogares monoparentales encabezados por mujeres y pobreza en Costa Rica}

\author{
T.H. Gindling y Luis Oviedo
}

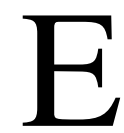

ingreso real medio de las familias en Costa Rica aumentó a fines de los años 1990 y comienzos de los años 2000, pero la pobreza no se redujo. Aquí se sostiene que en el país la aceleración del crecimiento económico no se tradujo en una caída de la pobreza porque la estructura familiar y el mercado laboral experimentaron cambios que tuvieron un importante sesgo de género. Concretamente, el incremento de hogares monoparentales encabezados por mujeres elevó el número de mujeres con hijos que se incorporaron a la fuerza laboral, muchas de ellas por primera vez. Estas no pudieron o no quisieron encontrar trabajos de jornada completa en el sector formal, donde las remuneraciones son más altas, y terminaron desempleadas o trabajando a jornada parcial por cuenta propia. Así, las condiciones del mercado de trabajo contribuyeron a los bajos ingresos de los hogares vulnerables, en especial aquellos monoparentales encabezados por mujeres. 


\section{Introducción}

Desde la década de 1970 hasta comienzos de la década de 1990 la pobreza en Costa Rica fue contracíclica, ya que se redujo en los períodos de expansión para luego aumentar en las fases recesivas. Sin embargo, entre 1996 y 2003, pese al incremento del ingreso real medio de las familias, la pobreza se mantuvo estacionaria (gráficos 1 y 2). En el presente trabajo se sostiene que en Costa Rica la aceleración del crecimiento económico no se tradujo en una caída de la pobreza porque la estructura familiar y el mercado laboral experimentaron cambios que tuvieron un importante sesgo de género. Se sostiene además que las variaciones de la estructura familiar guardaron relación con las registradas en el mercado laboral. Dicho en otras palabras, que el aumento de la proporción de hogares monoparentales ${ }^{1}$ encabezados por mujeres tuvo que ver con un incremento del número de mujeres con hijos pequeños que ingresaron a la fuerza de trabajo. Muchas de estas mujeres, que trabajaban por primera vez, no pudieron obtener o no quisieron aceptar empleos de jornada completa en el sector formal, donde las remuneraciones son más altas, y terminaron desempleadas o trabajando por cuenta propia en jornada parcial. Por su parte, estas condiciones del mercado de trabajo contribuyeron a aumentar la desigualdad y el desempleo y a mantener bajos los ingresos de las familias vulnerables, en especial aquellas monoparentales con jefa de hogar.

En CEPAL (2004) se señala que: "La tendencia más notable (de la estructura familiar en América Latina) es el aumento de los hogares monoparentales femeninos". El presente artículo ayuda a comprender en qué medida este cambio de la estructura familiar ha contribuido a la pobreza y a modificaciones del mercado laboral en un país latinoamericano.

El resto del estudio está estructurado de la siguiente manera. En la sección II se describen los cambios del mercado laboral costarricense que llevaron al estancamiento de la tasa de pobreza en el período 1996-2003. La sección III examina los cambios ocurridos en la estructura familiar y sostiene que tales cambios causaron en gran medida muchas de las alteraciones del mercado laboral que condujeron a una desigualdad creciente y a niveles de pobreza estacionarios. La sección IV contiene algunas conclusiones y señala posibles políticas.

GRÁFICO 1

Costa Rica: tasa de pobreza y de extrema pobreza, 1990-2003

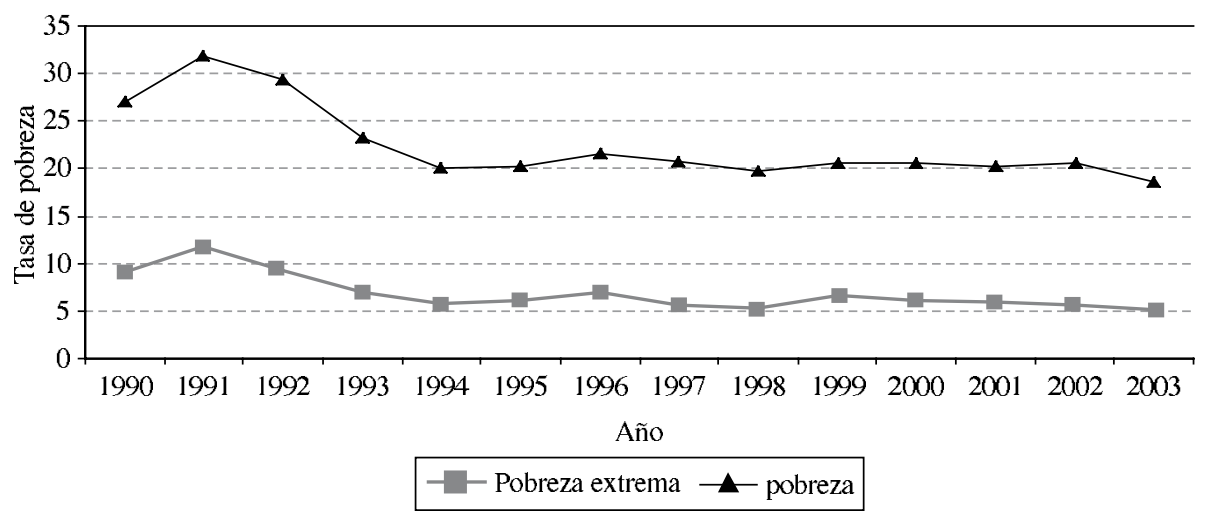

Fuente: Estado de la Nación, Costa Rica, 2006. Disponible en www.estadonacion.or.cr.

$\square$ Los autores agradecen las observaciones y sugerencias de Andrew Mason, Jaime Saavedra, Carlos Sobrado y Juan Diego Trejos. Una versión anterior del presente trabajo formó parte del estudio del mercado de trabajo elaborado bajo la supervisión de Andrew Mason y Carlos Sobrado para una evaluación de la pobreza en Costa Rica, del Banco Mundial, correspondiente al 2006.

${ }^{1}$ Definimos el hogar monoparental como aquel en que, según las Encuestas de Hogares de Propósitos Múltiples, no hay cónyuge ni compañero/a. 
GRÁFICO 2

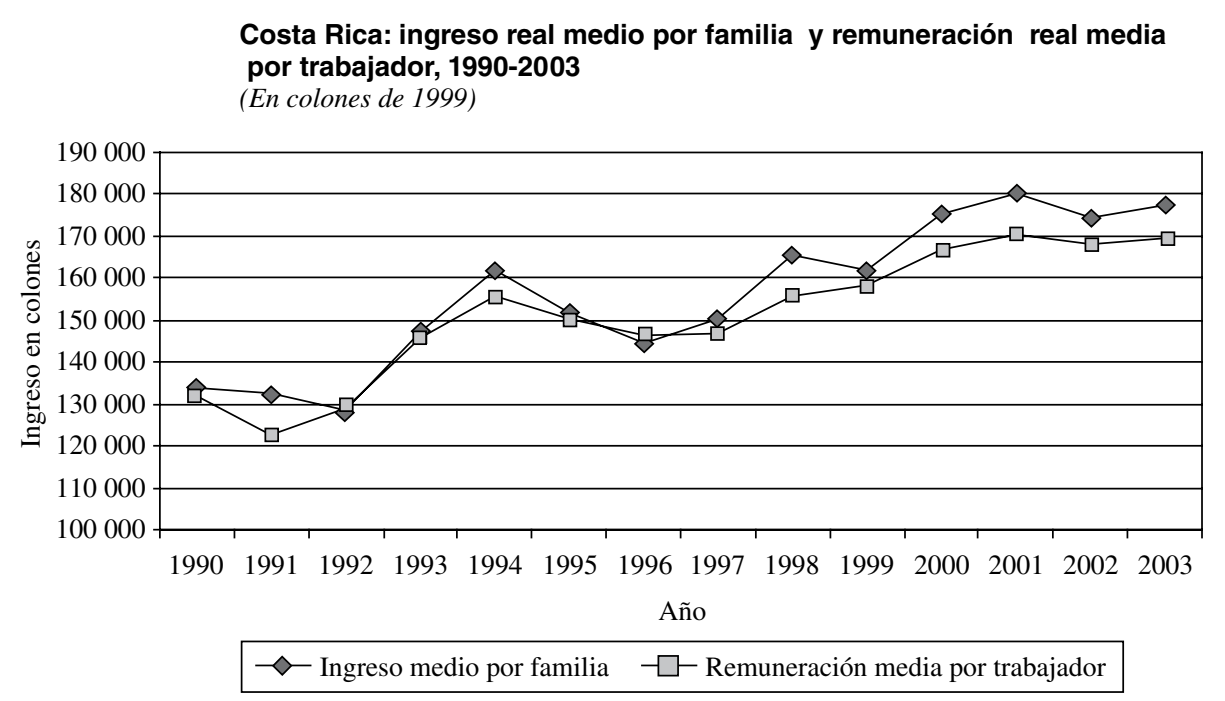

Fuente: Estado de la Nación, Costa Rica, 2006. Disponible en www.estadonacion.or.cr.

\section{II}

\section{Los cambios experimentados por el mercado laboral}

Dos fenómenos ocurridos en el mercado laboral contribuyeron a que en Costa Rica la pobreza se mantuviera estacionaria pese al crecimiento económico: i) el aumento de la desigualdad del ingreso y las remuneraciones y ii) el incremento del desempleo entre los miembros de los hogares pobres.

\section{El aumento de la desigualdad}

Tras disminuir durante al menos tres decenios (los de 1960, 1970 y 1980), a mediados de los años 1990 la desigualdad de las remuneraciones y del ingreso comenzó a acentuarse en el país (Gindling y Trejos, 2005). El gráfico 3 muestra que entre 1990 y 1995 la desigualdad de los ingresos de las familias se redujo, pero que entre 1995 y 2003 se acentuó, al mantenerse estacionaria la pobreza. ${ }^{2} \mathrm{El}$ aumento de la desigualdad de las remuneraciones y del ingreso fue una de las razones

\footnotetext{
${ }^{2}$ El gráfico 3 muestra el logaritmo de la varianza del ingreso, que es una medida de la desigualdad sensible a las fluctuaciones de los ingresos de los pobres. Otros indicadores de la desigualdad, como el coeficiente de Gini y el índice de Theil, siguen una pauta similar.
}

por las cuales los ingresos crecientes registrados en la segunda mitad del decenio de 1990 no se tradujeron en una pobreza decreciente.

En un estudio sobre los cambios en la desigualdad de las remuneraciones en Costa Rica, Gindling y Trejos (2005) concluyen que la agudización de esa desigualdad en los años 1990 obedeció principalmente al incremento de la proporción de trabajadores cuya jornada de trabajo era distinta de la normal —esto es, que cumplían jornada parcial o jornadas más largas que las habituales- en gran medida por el aumento de la proporción de mujeres que trabajaban por cuenta propia. ${ }^{3}$ Esto acentuó la disparidad de horas laboradas por los distintos trabajadores y, por ende, aumentó la diferencia entre las sumas que estos percibían por mes y por año. El incremento de la proporción de mujeres que trabajaban a jornada parcial y por cuenta propia también guarda relación con el estancamiento de la pobreza; entre 1996 y 2003 esa proporción se elevó de manera apreciable, del 42,7\%

\footnotetext{
${ }^{3}$ Otra razón del aumento de la disparidad en el número de horas trabajadas fue que en este período se elevó la proporción de hombres que trabajaron horas extraordinarias.
} 
al 49,5\%; en cambio, la proporción de hombres que trabajaban con la misma modalidad se mantuvo. ${ }^{4}$ Este patrón se apartó del registrado a comienzos del decenio de 1990, cuando la proporción de mujeres que trabajaban a jornada parcial se mantuvo estacionaria (en torno al
42,5\%). El gráfico 4 revela que si bien entre 1990 y el 2003 aumentó la proporción de hombres y de mujeres que trabajaban por cuenta propia, el incremento fue muy superior entre las mujeres (del $16 \%$ al $25 \%$ ) que entre los hombres (del 28\% al 29\%). Además, en 1990-2003,

GRÁFICO 3

Costa Rica: logaritmo de la varianza de las remuneraciones y el ingreso, 1990-2003

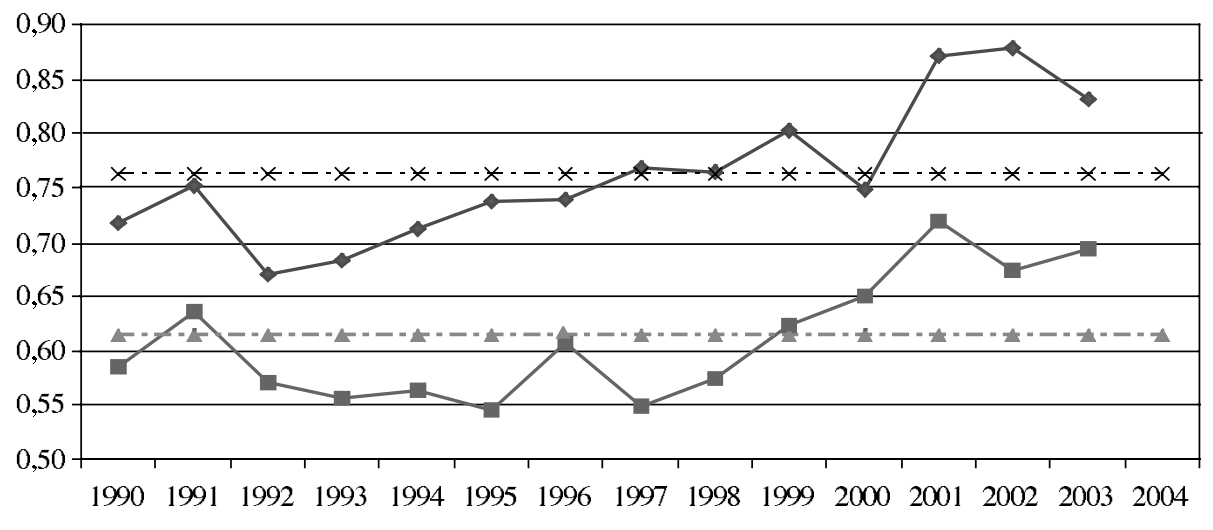

Aก̃o

\begin{tabular}{|ll|}
\hline$\longrightarrow$ Remuneraciones & Ingreso familiar \\
$-*--$ Remuneración media & -- \pm-- Ingreso familiar medio
\end{tabular}

Fuente: estimaciones de los autores con datos de las Encuestas de Hogares de Propósitos Múltiples, 1990-2003.

a Corresponde al promedio del logaritmo de la varianza de las remuneraciones.

b Corresponde al promedio del logaritmo de la varianza del in greso familiar.

GRÁFICO 4

Costa Rica: trabajadores por cuenta propia, según el género, 1990-2003 (Porcentajes)

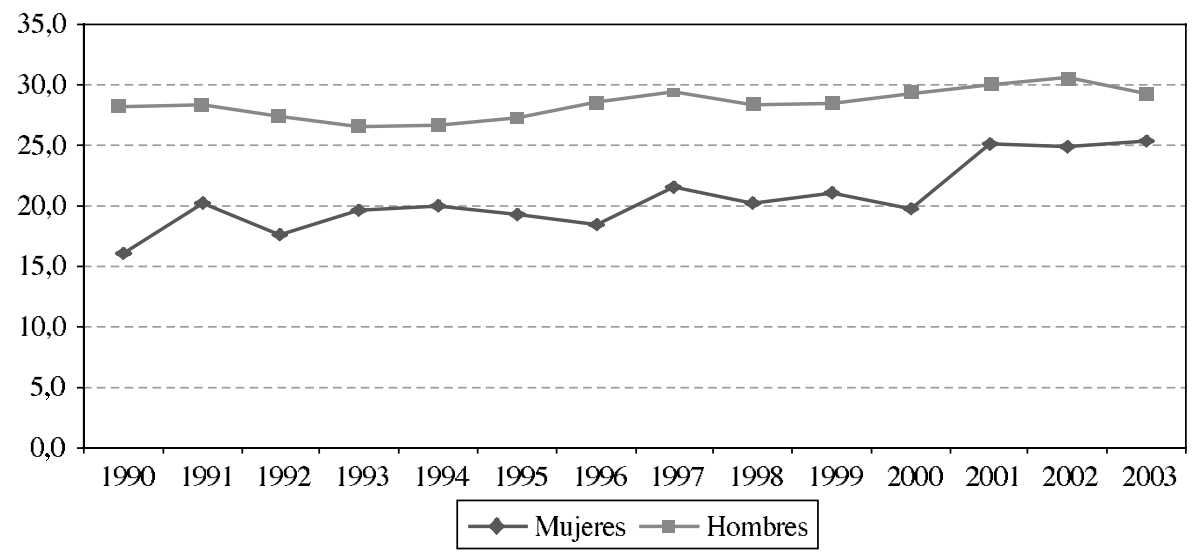

Fuente: estimaciones de los autores con datos de las Encuestas de Hogares de Propósitos Múltiples, 1990-2003.

\footnotetext{
${ }^{4}$ Según estimaciones de los autores autores, basadas en las Encuestas de Hogares de Propósitos Múltiples.
} 
Costa Rica: tasa de desempleo según situación en materia de pobreza, 1990-2003 (Porcentajes)

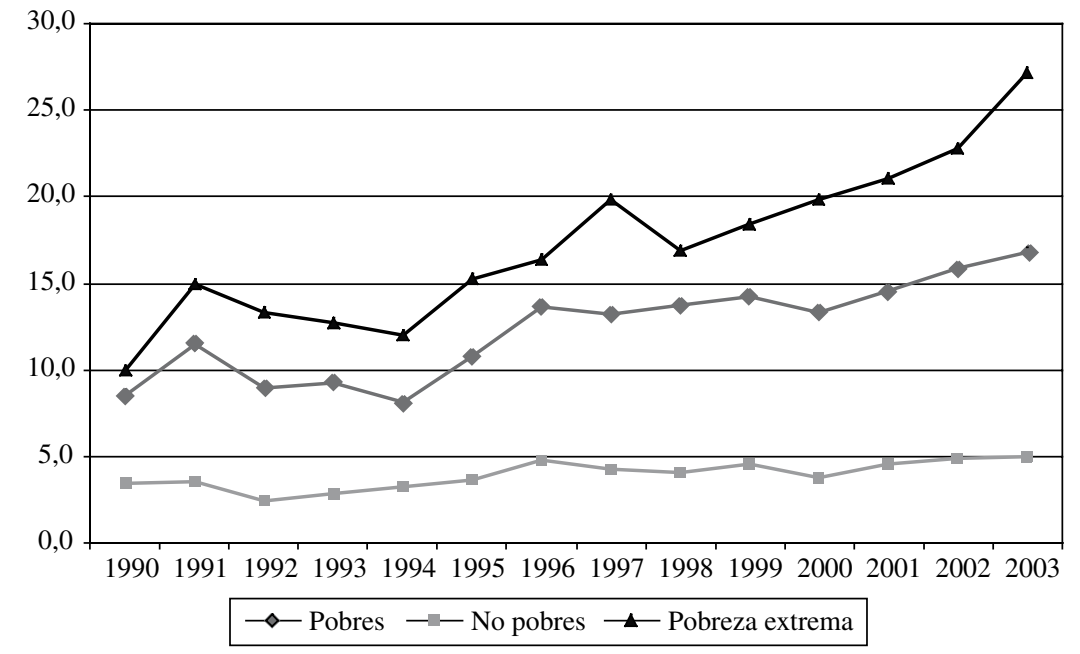

Fuente: estimaciones de los autores con datos de las Encuestas de Hogares de Propósitos Múltiples, 1990-2003.

período de estancamiento de la pobreza, la proporción de mujeres que trabajaban por cuenta propia aumentó con más rapidez que en 1990-2003, período en que las tasas de pobreza disminuyeron.

El aumento de la proporción de mujeres que trabajaban a jornada parcial se produjo principalmente entre aquellas de hogares pobres y contribuyó aún más a acrecentar la pobreza. En efecto, dicha proporción se elevó del $53 \%$ al $68 \%$ entre 1990 y el 2003 , mientras que entre las mujeres de hogares no pobres esta modalidad de trabajo también aumentó, pero a un ritmo más pausado (subió del $40 \%$ al 47\%). Al mismo tiempo, se redujo la proporción de hombres de hogares pobres y no pobres que trabajaban a jornada parcial, mientras que la de aquellos que trabajaban horas extraordinarias aumentó del $27 \%$ al $30 \%$ y del $35 \%$ al 41\%, respectivamente. De 1990 al 2003 la proporción de trabajadores por cuenta propia también creció más rápido entre las mujeres de hogares pobres: la proporción de estas últimas casi se duplicó, elevándose del $22 \%$ al $42 \%$, mientras que entre las mujeres de hogares no pobres subió de $40,8 \%$ a $47,4 \%$.

En resumen, el incremento de la desigualdad de remuneraciones registrado en el período 1996-2003 obedeció principalmente a que un mayor número de mujeres trabajó a jornada parcial por cuenta propia. $^{5}$

\footnotetext{
${ }^{5}$ Según Gindling y Trejos (2005), otros fenómenos del mercado laboral que contribuyeron a acentuar la desigualdad de salarios incluyen una acentuación de la diferencia entre los salarios de hombres y mujeres, la
}

Además, una mayor proporción de las mujeres que trabajaban de esa manera vivía en hogares pobres, lo que contribuyó a que aumentara la pobreza.

\section{El incremento del desempleo}

El aumento del ingreso real medio en circunstancias de que la pobreza se mantuvo estacionaria es un enigma que en parte se explica por el alza del desempleo, especialmente entre las personas más vulnerables. Hasta 1996 el desempleo a nivel nacional tuvo un comportamiento contracíclico: entre 1990 y 1994 se redujo (del 4,6\% al 3,5\%) para elevarse entre 1994 y 1996 debido a la crisis económica (a más del 6\% en este último año). Sin embargo, pese a que el producto interno bruto (PIB) per cápita y las remuneraciones e ingresos medios reales crecieron a partir de 1996, el desempleo continuó siendo alto $(6 \%-6,5 \%)$ hasta el 2003.

La elevada y creciente tasa de desempleo durante el período en que los ingresos aumentaron y la pobreza se mantuvo estacionaria afectó particularmente a las personas que vivían en hogares pobres. En el gráfico 5 se observa que entre las personas de hogares no pobres el desempleo se mantuvo ligeramente por debajo del 5\% durante el período de expansión (1996-2003), pero que

rentabilidad creciente de la educación y una desigualdad más marcada de los niveles educativos de los trabajadores. 
aumentó en forma sostenida y marcada en el caso de las personas de hogares pobres. Entre estas últimas, el desempleo subió de menos del 13\% al 16,7\%, mientras que en el caso de las personas en situación de pobreza extrema pasó del 16,3\% al 27,1\%.

A juzgar por nuestro análisis de los datos, las causas de las mayores tasas de desempleo fueron distintas para hombres y mujeres. En el caso de las mujeres el aumento del desempleo fue impulsado por su mayor participación en la fuerza laboral, mientras que en el de los hombres estuvo relacionado con las fluctuaciones de la demanda de trabajo. De 1990 al 2003, la tasa de participación en la fuerza laboral se incrementó entre las mujeres y se redujo entre los hombres (gráfico 6). Entre 1987 y 1996, la participación de las mujeres en la fuerza laboral varió muy poco, pero entre 1996 y el 2003 se elevó, coincidiendo con el período de crecimiento acelerado del ingreso y de estancamiento de la pobreza. El aumento de la participación de las mujeres en la fuerza de trabajo indica que, al menos en parte, la elevada y creciente tasa de desocupación fue estimulada por la oferta. Concretamente, postulamos que pese al incremento de la demanda de mano de obra y de empleo, este último no pudo aumentar al mismo ritmo que la participación de las mujeres en la fuerza de trabajo.

Para allegar evidencia adicional a esta hipótesis utilizamos una técnica desarrollada por Card y Riddell (1993) para descomponer el incremento de la tasa de desempleo (que se inició en 1994) en tres elementos, a saber: i) las variaciones de la tasa de no empleo (desempleo más no participación en la fuerza laboral como proporción de la población de más de 12 años), ii) las variaciones de la probabilidad de desempleo en condiciones de no empleo (desempleo más no participación en la fuerza laboral) y iii) las variaciones de la participación en la fuerza laboral. Los dos últimos elementos se relacionan con el alza de la participación en la fuerza laboral, mientras que el primero tiene que ver con las variaciones de la demanda de mano de obra.

Expresado formalmente, sean $P(U \mid L F)$ la probabilidad de desempleo dada la participación en la fuerza laboral (la tasa de desempleo), $P(N)$ la probabilidad incondicional de no empleo y $P(L F)$ la probabilidad de formar parte de la fuerza de trabajo. Luego,

$$
P(U \mid L F)=\frac{P(N) * P(U \mid N)}{P(L F)}
$$

Considerando los logaritmos,

$\log P(U \mid L F)=\log P(N)+\log P(U \mid N)-\log P(L F)$

Puesto que la participación de las mujeres en la fuerza laboral crece y la de los hombres disminuye, estimamos la proporción correspondiente por separado para unas y otros. En el caso de las mujeres, nuestras estimaciones

GRÁFICO 6

Costa Rica: participación en la fuerza laboral, según el género, 1990-2003 (Porcentajes)

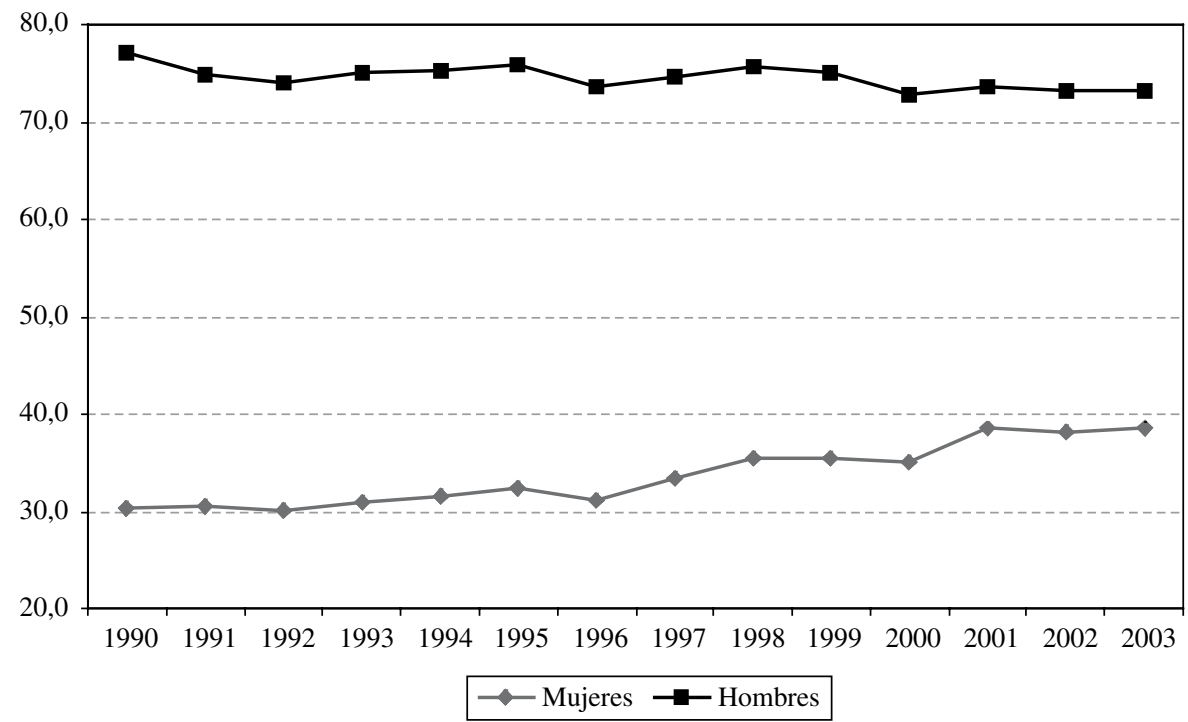

Fuente: estimaciones de los autores con datos de las Encuestas de Hogares de Propósitos Múltiples, 1990-2003. 
indican que la totalidad del incremento del desempleo entre 1994 y 2003 puede atribuirse al aumento de su participación en la fuerza laboral. En realidad, la tasa de no empleo (proporción de la población en edad de trabajar que se encuentra desempleada o que no se ha incorporado en la fuerza de trabajo) se redujo entre las mujeres, lo que indica que si no hubiesen aumentado sus tasas de participación en la fuerza laboral, la tasa de desempleo de las mujeres habría disminuido. En el caso de los hombres, nuestros cálculos indican que el incremento de las tasas de desempleo se explica por cambios en la demanda de mano de obra y aumento de la probabilidad de desempleo dado el no empleo. ${ }^{6}$ En síntesis, el incremento del desempleo entre los integrantes de hogares pobres en el período 1996-2003 obedeció en parte a una mayor participación de las mujeres en la fuerza laboral.

\section{III}

\section{Cambios en la estructura familiar}

En la sección anterior señalamos que en el período 1996-2003 la pobreza se mantuvo estacionaria en Costa Rica, pese al crecimiento económico, por las razones siguientes: el aumento de la proporción de mujeres de hogares pobres que trabajaban por cuenta propia a jornada parcial, y la mayor participación de mujeres de familias pobres en la fuerza laboral, lo que elevó la tasa de desempleo de los miembros de las familias pobres. En la presente sección demostramos que estos fenómenos del mercado laboral se relacionaron con cambios en la estructura de los hogares. Al respecto, el cambio más notable fue el aumento de la proporción de hogares encabezados por una mujer (de un $18 \%$ a un $25,5 \%$ del total de hogares en 1990-2003), y la caída consiguiente del número de familias biparentales "tradicionales" encabezadas por un hombre (del 61,6\% al 49,6\% de los hogares (cuadro 1). El incremento más marcado del número de hogares encabezados por una mujer se produjo en el período en que la tasa de pobreza se mantuvo estacionaria pese al crecimiento económico (1996-2003): la proporción se elevó del $20,7 \%$ al $25,5 \%$, en contraposición al aumento de solo 2,7 puntos porcentuales registrado entre 1990 y 1996. Además, en el decenio de 1990 aumentaron las probabilidades de que las familias pobres tuviesen jefas de hogar, ya que la proporción de hogares pobres encabezados por mujeres subió del $20,4 \%$ en 1990 al 33,0\% en 2003 (cuadro 1). En el período indicado también se elevó la proporción de hogares monoparentales con jefatura femenina entre los no pobres, aunque en este caso el incremento fue más reducido (del 17,2\% al 23,4\%).

$\mathrm{Al}$ examinar la relación de la estructura familiar con la pobreza es importante distinguir entre los hogares monoparentales encabezados por mujeres y aquellos sin hijos encabezados por mujeres. En general, las jefas de hogar no son necesariamente más pobres que los jefes de hogar. Por ejemplo, en CEPAL (2003) se concluye que en América Latina no se observa una diferencia sistemática en las tasas de pobreza de hogares monoparentales con jefes o con jefas de hogar. Algunos de los hogares encabezados por mujeres tienen menos probabilidades de ser pobres que el promedio de los hogares: por ejemplo, los que corresponden a un número cada vez mayor de mujeres jóvenes económicamente independientes de la región que figuran en los registros como hogares monoparentales encabezados por mujeres (CEPAL, 2004). ${ }^{7}$ Por otra parte, en casi todos los países de América Latina las tasas de pobreza son más altas para los hogares monoparentales encabezados por

\footnotetext{
${ }^{6}$ En el caso de las mujeres, el empleo como porcentaje de la población femenina en edad de trabajar se elevó del $29 \%$ en 1996 al $35 \%$ en el 2003. La variación total del logaritmo de la tasa de desempleo femenino entre 1994 y el 2003 fue de 0,35; a esta cifra contribuyeron las variaciones de la tasa de no empleo $(-0,08)$ y las relacionadas con cambios en la participación en la fuerza laboral $(0,43)$, es decir, el primero y el tercero de los componentes mencionados antes. En cuanto a los hombres, en el mismo período la variación del logaritmo de la tasa de desempleo fue de 0,52 , cifra de la cual 0,13 correspondió a las variaciones de la tasa de no empleo, 0,37 a las variaciones de la probabilidad de encontrarse desempleado dado el no empleo y 0,02 a las variaciones de la tasa de participación en la fuerza laboral.

${ }^{7}$ Slon y Zúñiga (2006), utilizando un conjunto de datos de panel sobre jefes de hogar construido a partir de las Encuestas de Hogares de Propósitos Múltiples 2000-2002, encontraron que los hogares monoparentales con jefatura femenina tienen menos probabilidades de salir de la pobreza que aquellos con jefatura masculina y que la probabilidad de que un hogar no pobre caiga en la pobreza es mayor cuando está encabezado por una mujer (tras controlar por otros factores que influyen en el proceso de transición hacia o desde la pobreza).
} 


\begin{tabular}{|c|c|c|c|}
\hline & 1990 & 1996 & 2003 \\
\hline \multicolumn{4}{|l|}{ Porcentaje de hogares en que: } \\
\hline Mujer es jefe de hogar & 18,0 & 20,7 & 25,5 \\
\hline Cónyuge ausente, hijos de hasta 18 años & 11,0 & 11,5 & 13,5 \\
\hline Cónyuge ausente, sin hijos & 6,2 & 7,8 & 9,2 \\
\hline Cónyuge presente, hijos de hasta 18 años & 0,6 & 0,9 & 1,9 \\
\hline Cónyuge presente, sin hijos & 0,2 & 0,4 & 0,9 \\
\hline Hombre es jefe de hogar & 8,0 & 79,3 & 74,5 \\
\hline Cónyuge ausente, con hijos de hasta 18 años & 1,7 & 1,7 & 1,7 \\
\hline Cónyuge ausente, sin hijos & 5,1 & 5,7 & 6,8 \\
\hline Cónyuge presente, hijos menores de 18 años & 61,6 & 56,6 & 49,6 \\
\hline Cónyuge presente, sin hijos & 13,6 & 15,3 & 16,3 \\
\hline \multicolumn{4}{|l|}{ Porcentaje de hogares pobres en que: } \\
\hline Mujer es jefe de hogar & 20,4 & 26,5 & 33,0 \\
\hline Cónyuge ausente, hijos de hasta 18 años & 13,4 & 16,8 & 22,5 \\
\hline Cónyuge ausente, sin hijos & 6,5 & 8,1 & 7,9 \\
\hline Cónyuge presente, hijos de hasta 18 años & 0,3 & 1,3 & 1,7 \\
\hline Cónyuge presente, sin hijos & 0,1 & 0,3 & 0,9 \\
\hline Hombre es jefe de hogar & 79,6 & 73,7 & 67,1 \\
\hline Cónyuge ausente, hijos de hasta 18 años & 1,8 & 1,4 & 2,0 \\
\hline Cónyuge ausente, sin hijos & 2,9 & 4,4 & 4,4 \\
\hline Cónyuge presente, hijos menores de 18 años & 65,2 & 57,0 & 50,7 \\
\hline Cónyuge presente, sin hijos & 9,2 & 10,7 & 9,9 \\
\hline Porcentaje de pobres (tasa de pobreza) de los siguientes hogares: & 27,1 & 21,5 & 18,5 \\
\hline Mujer jefe de hogar & 30,6 & 27,5 & 24,0 \\
\hline Cónyuge ausente, hijos de hasta 18 años & 32,9 & 31,5 & 30,9 \\
\hline Cónyuge ausente, sin hijos & 28,3 & 22,1 & 16,0 \\
\hline Cónyuge presente, hijos de hasta18 años & 14,3 & 29,6 & 16,1 \\
\hline Cónyuge presente, sin hijos & 15,0 & 14,2 & 17,1 \\
\hline Hombre jefe de hogar & 26,3 & 20,0 & 16,7 \\
\hline Cónyuge ausente, hijos de hasta 18 años & 28,0 & 17,9 & 22,6 \\
\hline Cónyuge ausente, sin hijos & 15,6 & 16,5 & 11,9 \\
\hline Cónyuge presente, hijos menores de 18 años & 28,7 & 21,6 & 18,9 \\
\hline Cónyuge ausente, sin hijos & 18,5 & 15,0 & 11,2 \\
\hline
\end{tabular}

Fuente: cálculos de los autores con datos de las Encuestas de Hogares de Propósitos Múltiples.

mujeres que para todos los demás tipos de hogares (CEPAL, 2004). Como puede verse en el cuadro 1, esto también se aplica a Costa Rica, donde las tasas de pobreza más altas corresponden a esta clase de hogares.

En Costa Rica, los hogares con jefatura femenina son en su gran mayoría monoparentales. Por lo general, las mujeres encabezan hogares monoparentales, en circunstancias de que los hogares encabezados por hombres suelen ser biparentales. Como también se observa en el cuadro 1, en Costa Rica la proporción de hogares pobres con jefatura femenina aumentó de 13,4\% en 1990 a 16,8\% en 1996 y a $22,5 \%$ en el 2003. En el período en que subieron los salarios pero la pobreza se estancó (1996-2003), el único tipo de hogar que elevó su participación en la pobreza fue el de los hogares monoparentales encabezados por mujeres. El incremento del número de este tipo de hogares que se hallaba en situación de pobreza no se debió a que entre ellos se elevara la tasa de pobreza — la que se mantuvo e incluso bajó levemente— - sino más bien a que se acrecentó la proporción de este tipo de hogares en la población en general. La proporción de hogares monoparentales encabezados por mujeres trepó del 11,5\% en 1996 al 13,5\% en el 2003, tras haber permanecido relativamente estable en 1990-1996.

En el período indicado, el incremento del número de hogares monoparentales y con jefatura femenina contribuyó directamente a mantener la tasa de pobreza, puesto que estos hogares tienen mayores probabilidades que otros de ser pobres. Esto obedece en parte a que en ellos es más probable que el salario de la mujer sea bajo. El cuadro 2 muestra las características de los hogares monoparentales encabezados por mujeres, tanto pobres como no pobres. Al comparar las características de las jefas de hogares monoparentales y las de los jefes de hogares biparentales "tradicionales" (cuadro 3 ), se observa que es más probable que las jefas de hogar carezcan de trabajo, 


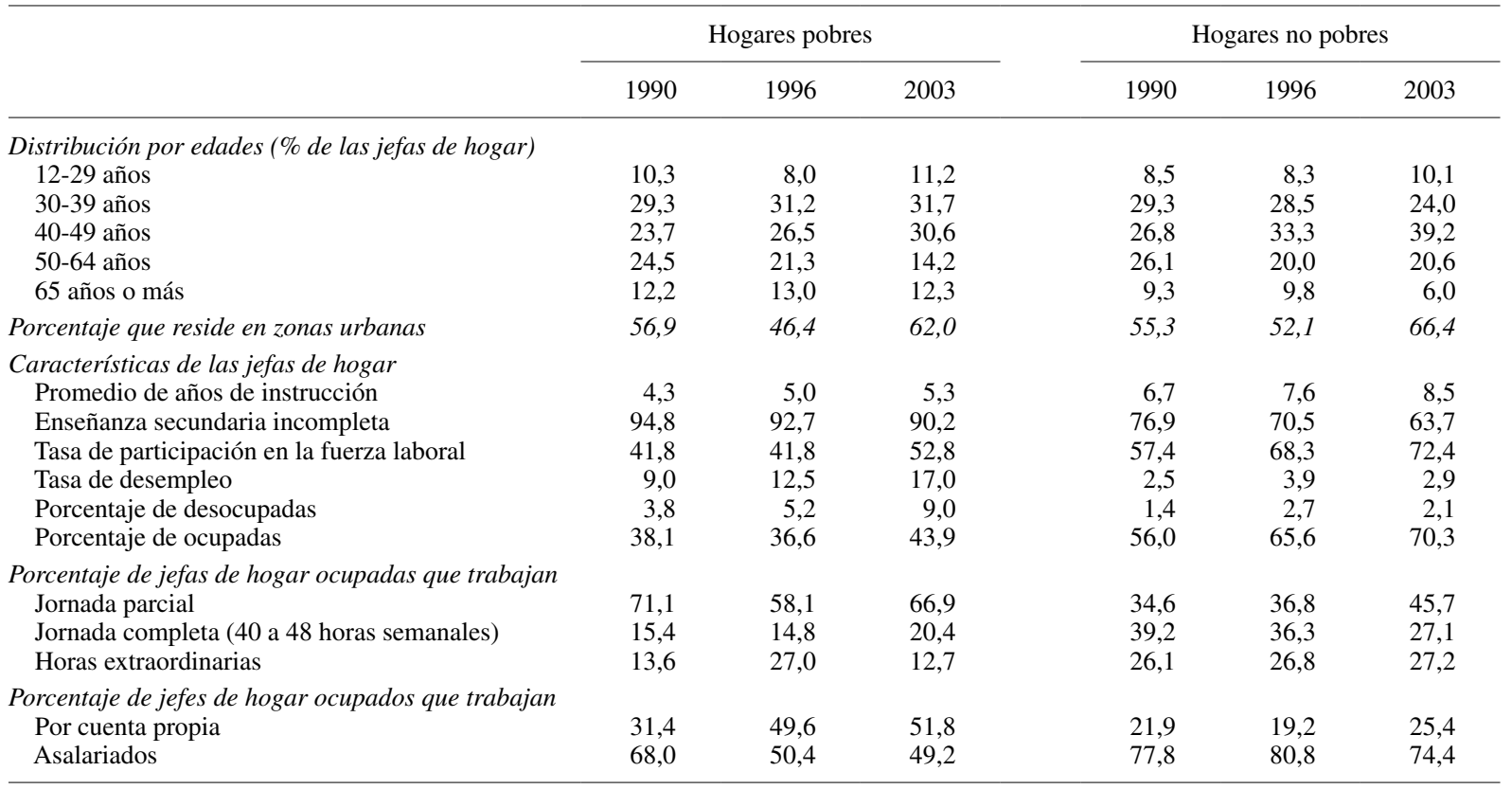

Fuente: estimaciones de los autores con datos de las Encuestas de Hogares de Propósitos Múltiples.

CUADRO 3

Costa Rica: características de los hombres jefes de hogar, con hijos de hasta 18 años y cónyuge presente, según situación en materia de pobreza, 1990, 1996 y 2003 (En porcentajes)

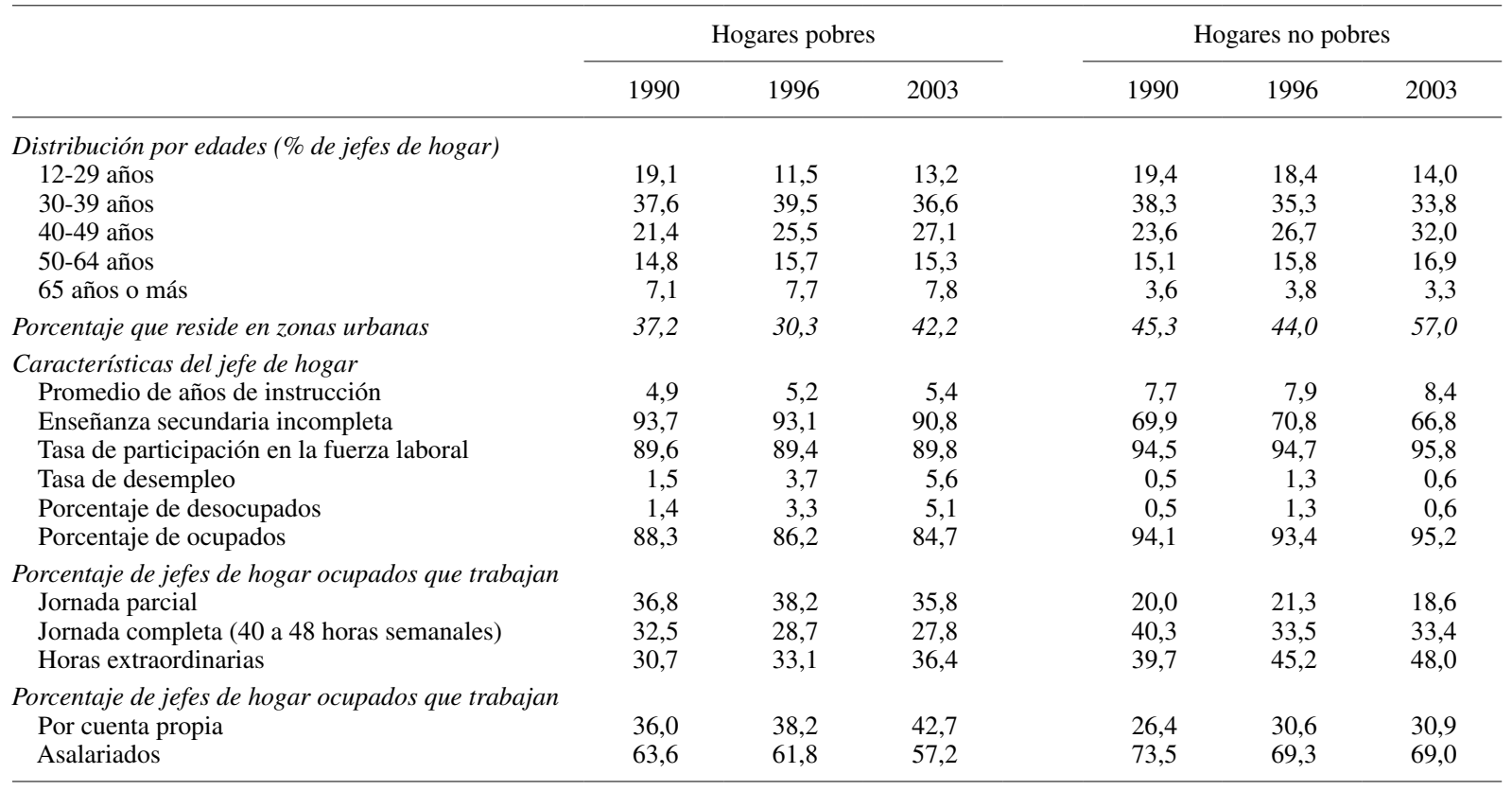

Fuente: cálculos de los autores con datos de las Encuestas de Hogares de Propósitos Múltiples. 
trabajen a jornada parcial o lo hagan por cuenta propia, fenómeno del mercado laboral al que hemos atribuido el incremento de la desigualdad y el estancamiento de la pobreza en el período 1996-2003. Comparadas con las jefas de hogares no pobres, las de hogares pobres tienen más probabilidades de participar en la fuerza de trabajo y de exhibir niveles de desempleo más altos y mayores probabilidades de trabajar a jornada parcial y por cuenta propia (cuadro 2).

Es más, entre 1996 y el 2003 (cuando la pobreza se mantuvo estacionaria pese al crecimiento económico) la participación en la fuerza laboral, el desempleo y el trabajo a jornada parcial y por cuenta propia tuvieron mayor peso en los hogares pobres con jefa de hogar. Por ejemplo, el cuadro 4 indica que casi todas las mujeres pobres que se incorporaron a la fuerza laboral pertenecían a hogares monoparentales con jefatura femenina: la proporción de trabajadoras pobres que vivían en esta clase de hogares se elevó del 36,4\% al 48,3\% entre 1990 y el 2003 (mientras que se redujo la de trabajadoras pobres que vivían en hogares con jefatura masculina y en hogares sin hijos encabezados por mujeres). Además, en 1996-2003 la proporción de jefas de hogares pobres con hijos que trabajaba a jornada parcial se elevó del $58,1 \%$ al $66,9 \%$, la proporción de las que trabajaban por cuenta propia aumentó del $49,6 \%$ al $51,8 \%$, el desempleo entre ellas subió del 5,2\% al 9,0\% y su participación en la fuerza laboral pasó del 41,8 al $52,8 \%$ (cuadro 2). Por otra parte, en el mismo período, en los hogares biparentales con jefe de hogar masculino bajaron las tasas de participación en la fuerza laboral y en el trabajo a jornada parcial. Si bien es cierto que en los hogares biparentales con jefatura masculina aumentaron las tasas de desempleo y de trabajo por cuenta propia, el incremento fue menor que en los hogares monoparentales con jefatura femenina, como se comprueba al comparar los cuadros 2 y 3 . Asimismo, entre 1996 y el 2003 los hogares monoparentales no pobres con jefatura femenina acusaron un incremento de la proporción de mujeres que trabajaba a jornada parcial (del 36,8\% al 45,7\%) y la de trabajadoras por cuenta propia (del 19,2\% al 25,4\%), y un descenso del desempleo del $2,7 \%$ al $2,1 \%$ (cuadro 2 ). ${ }^{8}$

\footnotetext{
8 Entre 1987 y 2004 también aumentó el número de hogares monoparentales con jefatura femenina y sin hijos (aunque a un ritmo menor que el de aquellos con hijos). En este caso, las mujeres generalmente eran mayores y las probabilidades de que participaran en la fuerza laboral eran menores que en el caso de las jefas de hogar con hijos y de los jefes de hogares biparentales "tradicionales". Más del $65 \%$ tenía 65 años o más, y menos del $10 \%$ formaba parte de la fuerza laboral. Esto indica que se trataba de mujeres de más edad que no tenían acceso a las pensiones de un cónyuge. Por desgracia, las encuestas de hogares no nos permiten dilucidar si se trataba de mujeres que nunca habían estado casadas, eran divorciadas o habían enviudado. Entre 1996 y 2003 también aumentó la proporción de
}

CUADRO 4

Costa Rica: estructura familiar y participación en la fuerza laboral de las mujeres que viven en hogares pobres, 1990, 1996 y 2003

(Porcentaje de la fuerza laboral femenina que vive en cada tipo de hogar)

\begin{tabular}{lrrr}
\hline & 1990 & 1996 & 2003 \\
\hline Mujeres jefes de hogar & 42,6 & 50,3 & 54,4 \\
Cónyuge ausente, hijos de hasta 18 años & 36,4 & 40,8 & 48,3 \\
Cónyuge ausente, sin hijos & 5,3 & 5,1 & 2,9 \\
Cónyuge presente, hijos de hasta 18 años & 0,7 & 3,9 & 2,6 \\
Cónyuge presente, sin hijos & 0,2 & 0,5 & 0,6 \\
Hombres jefes de hogar & 57,4 & 49,7 & 45,6 \\
Cónyuge ausente, hijos de hasta 18 años & 1,7 & 1,1 & 1,5 \\
Cónyuge ausente, sin hijos & 0,1 & 0,0 & 0,4 \\
Cónyuge presente, hijos menores de 18 años & 52,0 & 46,6 & 39,9 \\
Cónyuge presente, sin hijos & 3,6 & 2,1 & 3,9 \\
Total & 100,0 & 100,0 & 100,0 \\
\hline
\end{tabular}

Fuente: estimaciones de los autores con datos de las Encuestas de Hogares de Propósitos Múltiples.

En resumen, todo indica que el incremento de la proporción de hogares monoparentales encabezados por mujeres ayuda a explicar el fenómeno observado en el mercado laboral (tasas más altas de participación en la fuerza de trabajo, mayor desempleo y aumento del número de personas que trabajan por cuenta propia); ese fenómeno contribuyó a que en Costa Rica la pobreza se mantuviera estacionaria y a que aumentara la desigualdad de los ingresos. Por desgracia, las Encuestas de Hogares de Propósitos Múltiples no nos permiten identificar los orígenes sociológicos del aumento de los hogares monoparentales encabezados por mujeres. Por ejemplo, no podemos decir si se trata de mujeres que nunca estuvieron casadas, se casaron pero se divorciaron o enviudaron, o han vivido en uniones libres pero en su hogar ya no vive otro adulto. Este es un tema interesante para nuevos estudios. ${ }^{8}$

mujeres casadas de hogares con jefatura masculina que ingresó a la fuerza de trabajo. En ese mismo período un creciente porcentaje de mujeres casadas que vivían en hogares pobres y tenían hijos se incorporaron a la fuerza de trabajo (la proporción se elevó del 11,5\% al 13,5\%). Para las mujeres casadas de hogares pobres aumentaron las tasas de empleo y desempleo (como porcentaje de la población). Entre las ocupadas aumentaron las que trabajaban a jornada parcial o por cuenta propia. El incremento de la proporción de hogares en que la cónyuge trabaja explica en parte el aumento de los trabajadores a jornada parcial o por cuenta propia; sin embargo, no contribuye a explicar el estancamiento de la pobreza, puesto que generalmente el hecho de contar con dos proveedores de ingreso hace menos probable que un hogar sea pobre. En rigor, hay indicios de que la mayor participación en la fuerza laboral de las cónyuges que viven en hogares biparentales se tradujo en una disminución de la pobreza. En Costa Rica, la proporción de hogares en que ambos cónyuges trabajan aumentó más entre los hogares no pobres que entre los hogares pobres: la proporción de hogares con jefatura masculina y cónyuge que trabaja subió del $6,7 \%$ al $12,8 \%$ entre 1996 y el 2003 , mientras que en los hogares no pobres esta proporción se elevó del $24,4 \%$ al $32,2 \%$. 


\section{V}

\section{Conclusiones y posibles políticas}

El período en que la pobreza se mantuvo estacionaria en Costa Rica pese al incremento del ingreso real medio coincidió con un aumento apreciable del número de hogares con jefatura femenina y uno aún mayor de la proporción de hogares monoparentales pobres encabezados por mujeres. Puesto que los hogares monoparentales encabezados por mujeres tienen probabilidades mucho mayores de ser pobres que cualquier otro tipo de hogar, el solo hecho de que su número se acrecentara elevó las tasas de pobreza. Lo anterior es coherente también con que estas mujeres recién incorporadas a la fuerza laboral no pudieran o no quisieran buscar trabajo en el sector formal, que paga salarios más altos, y terminaran desempleadas o trabajando en jornada parcial por cuenta propia. Estas particularidades del mercado de trabajo contribuyeron a su vez a acrecentar la desigualdad, el desempleo y los bajos salarios en los hogares vulnerables a la pobreza.

Los resultados de nuestro estudio revelan que en Costa Rica muchas madres pobres deben enfrentar solas el cuidado de los hijos, lo que puede dificultarles el cumplimiento de horarios de trabajo normales en el sector formal. La pobreza podría reducirse con políticas que ayudaran a estas mujeres a obtener empleo en dicho sector y a cumplir allí una jornada de trabajo completa. Al mismo tiempo, si las familias pobres tuvieran mayor acceso a servicios de cuidado de los hijos durante los horarios normales de trabajo, a las madres solas pobres les resultaría más fácil encontrar trabajo a jornada completa bien remunerado. Las políticas públicas que tienen este objetivo incluyen: la ampliación de subsidios a las familias pobres destinados a este fin, programas de atención infantil antes y después de la jornada escolar, y subsidios a las empresas privadas para que presten servicios de guardería en el lugar de trabajo.

Trejos (2006) describe los programas de esta índole que existen en Costa Rica, entre otros, el de Centros Infantiles del Ministerio de Salud Pública y el programa Oportunidades de Atención a la Niñez, del Instituto Mixto de Ayuda Social (IMAs); no obstante, pone de relieve que tales programas solo favorecen a una proporción reducida de las familias pobres que necesitan servicios de atención a la niñez y que el gasto en estos servicios, de por sí pequeño, ha disminuido a partir del 2000. Además, ellos solo están destinados a niños en edad preescolar. En el caso de los niños en edad escolar, el Ministerio de Educación ofrece programas que ayudan a las familias a mantener a los hijos en la escuela (como los de almuerzo gratuito o ayuda financiera para transporte, uniformes, útiles escolares, etc.); sin embargo, no existen programas para el cuidado de estos niños antes y después de la jornada escolar. Esto limita las posibilidades de trabajo de las madres, porque muchas escuelas costarricenses funcionan en dos turnos diarios: puede suceder que un niño tenga clases solo en la mañana o únicamente en la tarde, por lo cual requerirá cuidado la otra mitad del día laboral de la madre.

Los resultados que hemos obtenido indican que Costa Rica debería reducir los obstáculos legales con que tropiezan las mujeres que querrían trabajar en horarios distintos del ordinario. Por ejemplo, actualmente la legislación prohíbe el trabajo nocturno de las mujeres, lo que podría obligar a las que quieran trabajar media jornada o jornada nocturna a sumarse al sector informal, con remuneraciones más bajas.

Por último, nuestro estudio lleva a concluir que el gobierno costarricense debería aplicar políticas que proporcionen a las madres solas la capacitación y demás recursos necesarios para que encuentren y conserven empleos bien remunerados. Las jefas de hogares monoparentales pobres tienen muy poca calificación si se las compara con otros trabajadores costarricenses; por lo tanto, los programas destinados a superar tal carencia podrían ayudar a reducir la pobreza en el país. Un conjunto de políticas de esta naturaleza contribuiría a que las mujeres (en especial las más jóvenes con hijos) completaran más años de educación formal. Otro conjunto de políticas podría proporcionar capacitación a madres solas adultas. Los actuales programas de capacitación no focalizados de Costa Rica incluyen los que lleva a cabo el Instituto Nacional de Aprendizaje (INA), el Instituto de Desarrollo Agrario (IDA) y el Consejo Nacional de Producción (CNP). Adicionalmente, el IMAS administra programas de capacitación orientados a los pobres (en especial a las jefas de hogar). Los resultados de nuestro estudio apuntan a que el gobierno debería ampliar programas de esta índole destinados a capacitar a las mujeres pobres. 


\section{Bibliografía}

Card, D. y W. C. Riddell (1993): A comparative analysis of unemployment in Canada and the United States, en D. Card y R. Freeman (comps.), Small Differences That Matter, Chicago, University of Chicago Press.

CEPAL (Comisión Económica para América Latina y el Caribe) (2003): Pobreza y desigualdad desde una perspectiva de género, Panorama social de América Latina y el Caribe, 2002-2003, LC/G.2209-P, Santiago de Chile. Publicación de las Naciones Unidas, $\mathrm{N}^{\mathrm{o}}$ de venta: S.03.II.G.185.

(2004): Estructuras familiares, trabajo doméstico y bienestar en América Latina, Panorama social de América Latina 2004,
LC/L.2220-P, Santiago de Chile. Publicación de las Naciones Unidas, $\mathrm{N}^{\mathrm{o}}$ de venta: S.04.II.G.148.

Gindling, T.H. y J. D. Trejos (2005): Accounting for changing inequality in Costa Rica: 1980-99, Journal of Development Studies, vol. 41, $\mathrm{N}^{\mathrm{o}}$ 5, Londres, Taylor and Francis, julio.

Slon, P. y E. Zúniga (2006): Dinámica de la pobreza en Costa Rica: datos de panel a partir de cortes transversales, Revista de la CEPAL, № 89, LC/G.2312-P, Santiago de Chile, Comisión Económica para América Latina y el Caribe (CEPAL), agosto.

Trejos, J. D. (2006): Pobreza y protección social en Costa Rica, informe preparado para el Banco Mundial, San José. 